\title{
Green silver nanoparticles of Phyllanthus amarus: as an antibacterial agent against multi drug resistant clinical isolates of Pseudomonas aeruginosa
}

\author{
Khushboo Singh', Manju Panghal ${ }^{1}$, Sangeeta Kadyan ${ }^{1}$, Uma Chaudhary ${ }^{2}$ and Jaya Parkash Yadav ${ }^{1 *}$
}

\begin{abstract}
Background: Pseudomonas aeruginosa infection is a leading cause of morbidity and mortality in burn and immune-compromised patients. In recent studies, researchers have drawn their attention towards ecofriendly synthesis of nanoparticles and their activity against multidrug resistant microbes. In this study, silver nanoparticles were synthesized from aqueous extract of Phyllanthus amarus. The synthesized nanoparticles were explored as a potent source of nanomedicine against MDR burn isolates of $P$. aeruginosa.

Results: Silver nanoparticles were successfully synthesized using $P$. amarus extract and the nature of synthesized nanoparticles was analyzed by UV-Vis spectroscopy, transmission electron microscopy, energy dispersive X-ray spectroscopy, dynamic light scattering, zeta potential, X- ray diffraction and fourier transform infra-red spectroscopy. The average size of synthesized nanoparticles was 15.7, $24 \pm 8$ and $29.78 \mathrm{~nm}$ by XRD, TEM and DLS respectively. The antibacterial activity of AgNPs was investigated against fifteen MDR strains of $P$. aeruginosa tested at different concentration. The zone of inhibition was measured in the range of $10 \pm 0.53$ to $21 \pm 0.11 \mathrm{~mm}$ with silver nanoparticles concentration of 12.5 to $100 \mathrm{\mu g} / \mathrm{ml}$. The zone of inhibition increased with increase in the concentration of silver nanoparticles. The MIC values of synthesized silver nanoparticles were found in the range of 6.25 to $12.5 \mu \mathrm{g} / \mathrm{ml}$. The MIC values are comparable to the standard antibiotics.

Conclusion: The present study suggests that silver nanoparticles from $P$. amarus extract exhibited excellent antibacterial potential against multidrug resistant strains of $P$. aeruginosa from burn patients and gives insight of their potential applicability as an alternative antibacterial in the health care system to reduce the burden of multidrug resistance.
\end{abstract}

Keywords: Pseudomonas aeruginosa, Burn isolates, MDR, Phyllanthus amarus, Silver nanoparticles, Antibacterial

\section{Background}

Pseudomonas aeruginosa, a gram negative bacterium, is the leading cause of morbidity and mortality in burn patients as they are more susceptible to infections because of immune-suppression and loss of cutaneous coverage [1]. Since $P$. aeruginosa has innate potential to develop resistance, virtually to any antibiotics to which it is exposed, due to the presence of multiple resistance mechanisms and it becomes a multidrug resistant (MDR) strain.

\footnotetext{
* Correspondence: yadav1964@rediffmail.com

'Department of Genetics, M.D. University, Rohtak 124001, Haryana, India Full list of author information is available at the end of the article
}

Infections caused by MDR $P$. aeruginosa are often severe; life threatening and these strains have frequently been reported as the cause of nosocomial infections. These MDR have been emerged as a major problem in burn units as burn injury disrupts both the normal skin barrier and many of systemic host defence mechanism which make burn patients the ideal hosts for opportunistic infections [2]. The importance to prevent these infections has been recognized since its inception thus it becomes difficult to treat the infection caused by $P$. aeruginosa MDR strains due to their narrow range of susceptibility to antimicrobial agents. Therefore, currently, researchers started to develop 
alternative therapies to aid patients to recover from the infections. In future, these alternatives may be useful in treating not only burn infections but other antibiotic resistant infections as well.

Nanotechnology provides a good platform to modify and develop the important properties of silver metal in the form of nanoparticles having promising applications as an antibacterial agent $[3,4]$. Silver nanoparticles have high surface area to volume ratio and the unique chemical, physical properties $[5,6]$. Nowadays, they have been widely used as an effective bactericidal agent against broad spectrum of bacteria, including antibiotic resistant strains [7]. Hence, researchers are shifting towards nanoparticles in general and silver nanoparticles (AgNPs) in particular to solve the problem of emergence of MDR bacteria [8]. Also the development of biological approach for the synthesis of nanoparticles is evolving in to an important branch of nanotechnology $[9,10]$. The biological method has advancement over chemical and physical method as it is cost effective and ecofriendly $[11,12]$. Phyllanthus amarus is an important plant of Indian Ayurvedic system of medicine, belongs to the family Euphorbiaceae. It is a small herb well known for its medicinal properties and has been used worldwide [13].

This study aims to explore the efficacy of synthesized silver nanoparticles from $P$. amarus as a potent source of nanomedicine against MDR burn isolates of $P$. aeruginosa and establish the therapeutic antibacterial potential of plant with nanotechnology; thereby justify the folklore claim of the plant used in the traditional system of Indian medicine.

\section{Results}

\section{Synthesis of AgNPs}

The AgNPs were successfully synthesized using aqueous plant extract of $P$. amarus by mixing with silver nitrate solution (1mM). The colour changes from pale yellow to dark brown (Additional file 1: Figure S1). This was observed due to the reduction of $\mathrm{Ag}^{+}$and it indicates the formation of AgNPs.

\section{Characterization of $\mathrm{Ag}$ nanoparticles}

The synthesis of AgNPs was confirmed by UV-VIS spectrophotometer (Shimadzu). The UV-VIS absorption spectra of the AgNPs were monitored in a range of 300-800 nm. A strong peak specific for the synthesis of silver nanoparticles was obtained at 420-430 nm. Additional file 2: Figure S2 shows the absorption spectra of AgNPs synthesized by $P$. amarus. The TEM results (Figure 1) showed that all synthesized AgNPs were spherical in shape with $24 \pm 8 \mathrm{~nm}$ size and found to be well dispersed in aqueous medium. EDX characterization has shown absorption of strong silver signal along with other elements, which may be originated from the

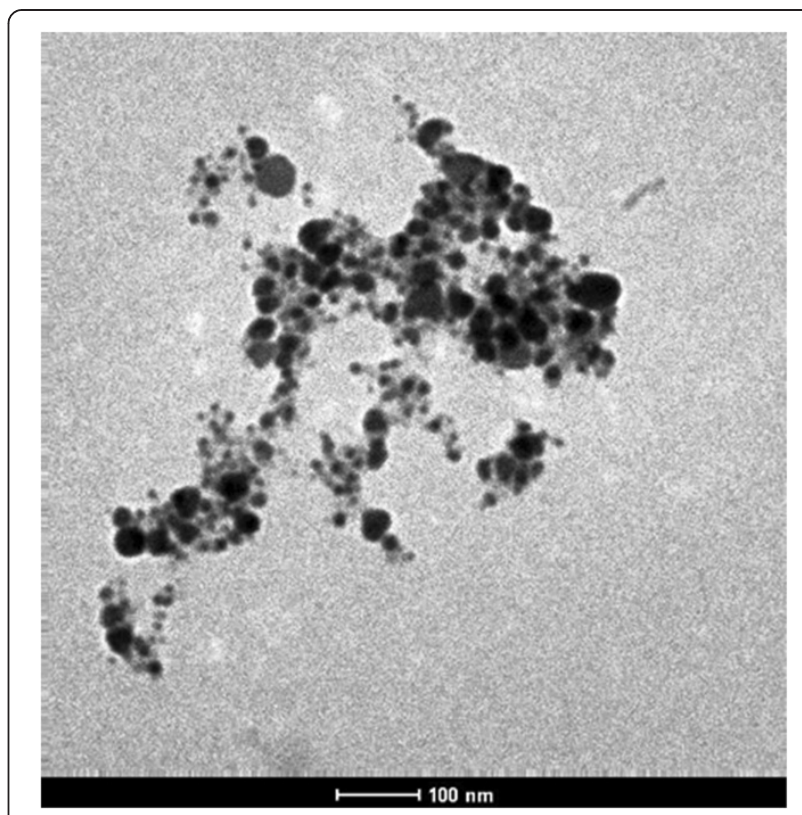

Figure 1 Image of TEM of silver nanoparticles of $P$. amarus. Figure showing picture of transmission electron microscopy of silver nanoparticles of $P$. amarus.

biomolecules that are bound to the surface of silver nanoparticles. EDX performed by energy and intensity distributions of X-ray signals generated by focused electron beam on a specimen. From EDX spectra, showed in Figure 2, it is clear that silver nanoparticles reduced by P. amarus.

Dynamic light scattering (DLS) technique and zeta potential has been used to determine the size of particles and measure the potential stability of the particles in the colloidal suspension respectively. Figure 3 and Figure 4 have shown the DLS and zeta potential graph of AgNPs of $P$. amarus with an average size of $29.78 \mathrm{~nm}$ and the particles carry a charge of $-11.9 \mathrm{mV}$ respectively. Silver nanoparticles generally carry a negative charge. All silver nanoparticles synthesized from $P$. amarus showed negative charge and were stable at room temperature. The particle size and nature of AgNPs was determined by XRD. The mean particle diameter of AgNPs was calculated using the Debye-Scherrer's equation. An average size of the silver nanoparticles synthesized by $P$. amarus was $15.7 \mathrm{~nm}$ (Figure 5 and Table 1). The FT-IR spectrum of AgNPs from P. amarus showed the characteristics absorbance bands (Figure 6) due to aldehydic $\mathrm{C}-\mathrm{H}$ stretch $\left(2,915\right.$ and $\left.2,848 \mathrm{~cm}^{-1}\right)$, C-O stretch $\left(1,634 \mathrm{~cm}^{-1}\right)$, $\mathrm{N}-\mathrm{H}\left(1517 \mathrm{~cm}^{-1)} 1462 \mathrm{~cm}^{-1} \mathrm{~N}-\mathrm{O}\right.$ stretch $\left(1,377 \mathrm{~cm}^{-1}\right)$ and C-O stretch (dialkyl) $\left(1,169 \mathrm{~cm}^{-1}\right), \mathrm{C}-\mathrm{N}\left(1,037 \mathrm{~cm}^{-1}\right), \mathrm{C}-\mathrm{H}$ stretch $\left(718 \mathrm{~cm}^{-1}\right)$.

\section{Antibacterial assay}

The 15 multidrug resistant strains of $P$. aeruginosa isolated from burn patients tested at various concentrations 


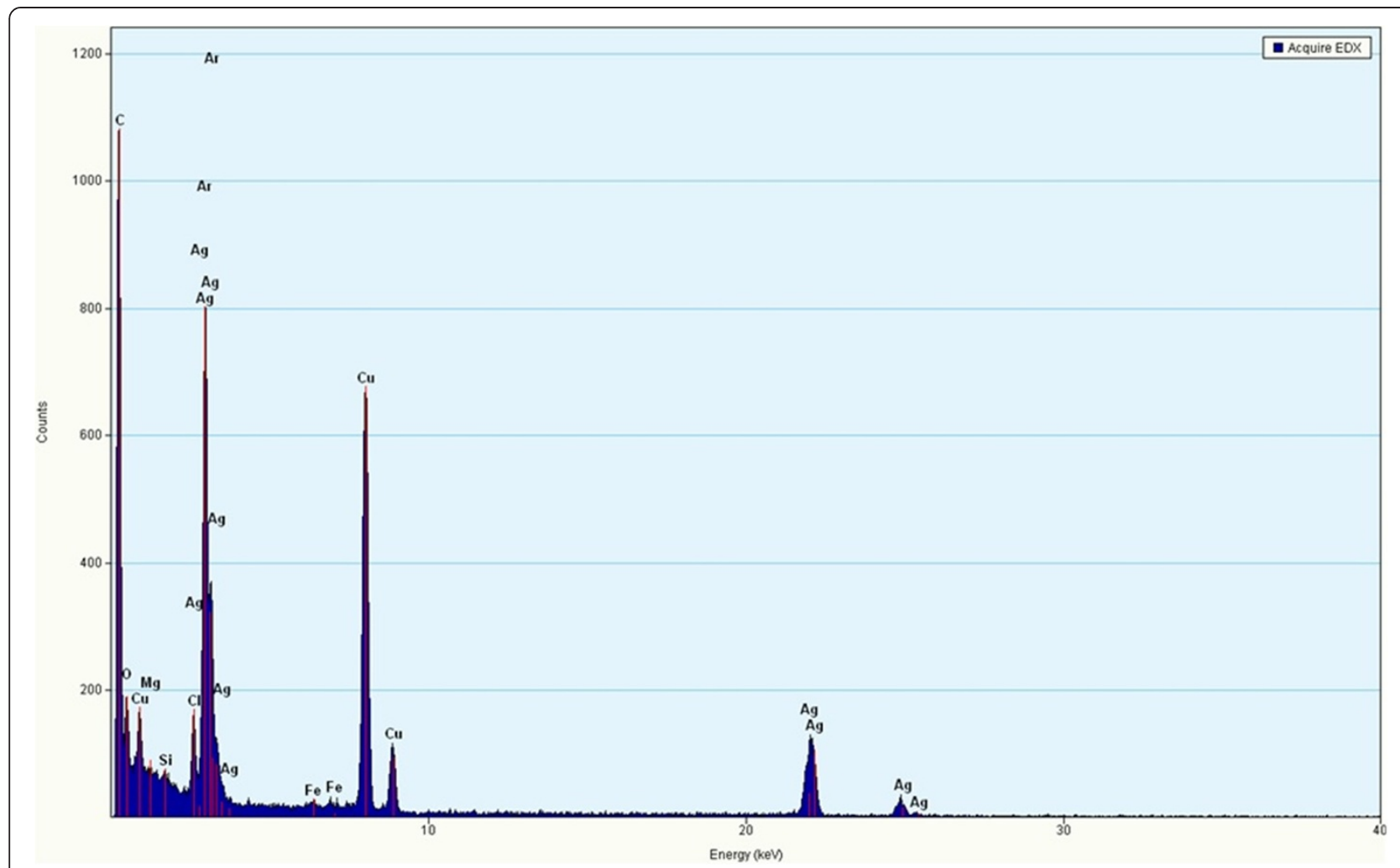

Figure 2 Image of EDX of silver nanoparticles of $P$. amarus. Figure showing picture of energy dispersive x-ray spectroscopy of silver nanoparticles of $P$. amarus.

of AgNPs i.e. 12.5, 25, 50 and $100 \mu \mathrm{g} / \mathrm{ml}$ to determine the antibacterial effect by agar well diffusion method. The AgNPs showed (Additional file 3: Figure S3) antimicrobial activity against all the tested pathogens. The antibacterial activity is concentration dependent as it increased with the concentration of AgNPs (Figure 7). The zone of inhibition measured in a range of $10 \pm 0.53$ to $21 \pm 0.11 \mathrm{~mm}$. MDR Strain1 was found (Figure 8) to be most susceptible where zone of inhibition ranged from $13 \pm 1$ to $21 \pm 0.11 \mathrm{~mm}$ at AgNPs concentration of 12.5 to $100 \mu \mathrm{g} / \mathrm{ml}$. MDR strain 10 was least susceptible with $10 \pm 0.53$ to $13 \pm 0.41 \mathrm{~mm}$ zone of inhibition.

\section{Minimum Inhibitory Concentration (MIC)}

The MIC of AgNPs from P. amarus against MDR strains of $P$. aeruginosa was $6.25-12.5 \mu \mathrm{g} / \mathrm{ml}$. MDR strains 6 , $10,12,13,14$ and 15 showed the MIC values of $12.5 \mu \mathrm{g} / \mathrm{ml}$. The remaining nine MDR strains have shown the MIC at $6.25 \mu \mathrm{g} / \mathrm{ml}$ (Table 2) which is lower than standard antibiotic.

\section{Discussion}

The biosynthesis of nanoparticles has received considerable attention due to the growing need to develop environmentally benign technologies in material synthesis [14]. The phytochemicals derived from plant products

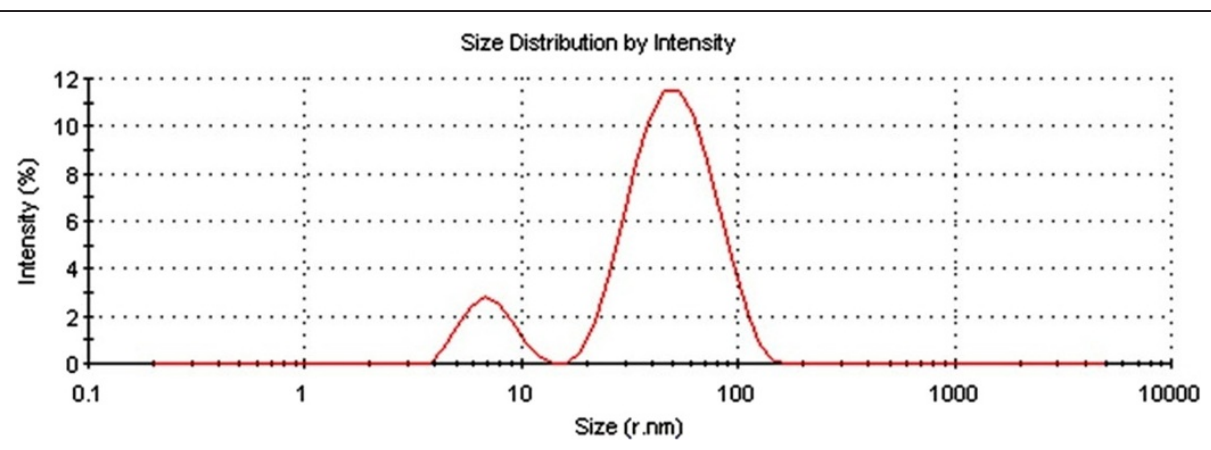

Figure 3 DLS graph of silver nanoparticles of $P$. amarus. Figure showing graph of dynamic light scattering of silver nanoparticles of $P$. amarus. 
Zeta Potential Distribution

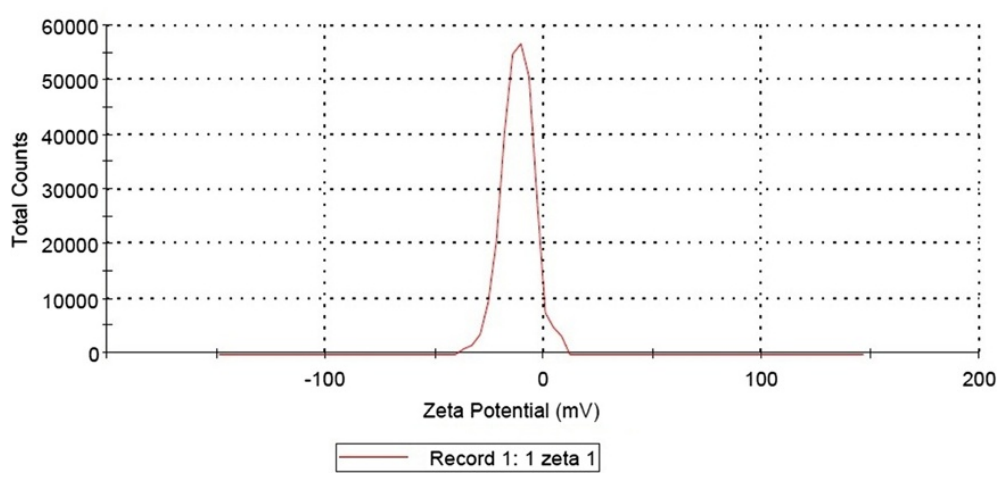

Figure 4 Zeta potential graph of silver nanoparticles of $P$. amarus. Figure showing graph of zeta potential of silver nanoparticles of $P$. amarus.

serve as a prototype to develop less toxic and more effective medicines for controlling the growth of microorganisms [15]. These compounds have significant therapeutic application against human pathogens. Numerous studies have been conducted with the extracts of various plants for screening of antimicrobial activity in search of new antimicrobial compounds [16]. P. amarus was also reported to have antibacterial efficacy against some drug resistant pathogenic bacterial strains [17]. But there are still limited studies regarding antibacterial activity of AgNPs from this plant. The beauty of the present study is that AgNPs reduced by $P$. amarus were highly effective against MDR burn isolates of $P$. aeruginosa in term of novelty. We synthesized AgNPs from P. amarus, which is easily available in rainy season, safe, non-toxic and have a variety of secondary metabolites that can help in the reduction of silver ions. The main mechanism considered for the process is plant-assisted reduction due to phytochemicals. The main phytochemicals involved are terpenoids, flavones, ketones, aldehydes, amides, and carboxylic acids. Flavones, organic acids, and quinones are watersoluble phytochemicals that are responsible for the immediate reduction of the ions [18]. Studies have revealed that $P$. amarus contain mainly phyllanthin, hypophyllanthin, phyltertralin and many more other phytochemicals [19]. It was also suggested that the phytochemicals are involved directly in the reduction of the ions and formation of silver nanoparticles [20]. Though the exact

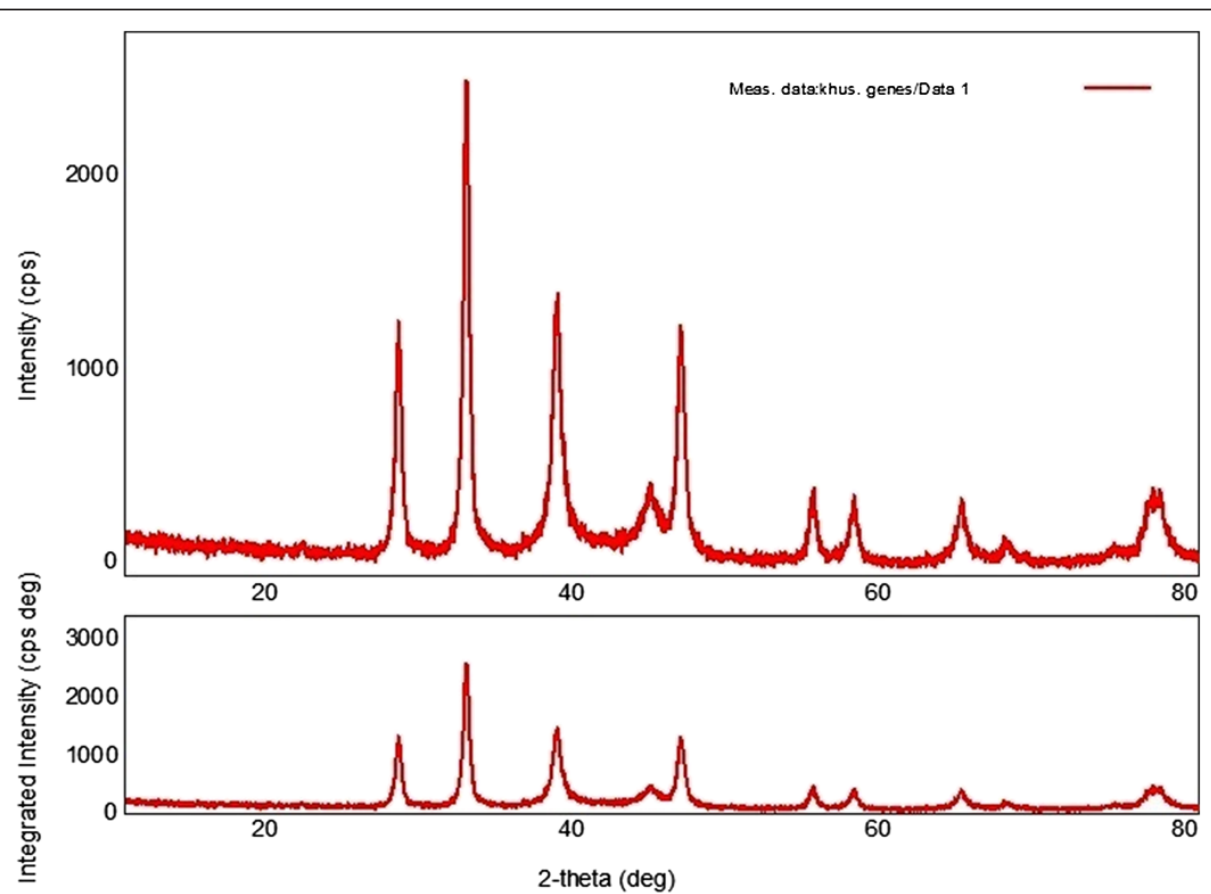

Figure 5 XRD of silver nanoparticles of $P$. amarus. Figure showing X-Ray Diffraction pattern of silver nanoparticles of $P$. amarus. 
Table 1 Size of AgNPs of $P$. amarus by using Debye-Scherrer's equation

\begin{tabular}{|c|c|c|c|c|c|c|}
\hline S. No. & 2-theta(deg) & D (ang.) & FWHM(deg) & Int. I(cps deg) & Int. W(deg) & Size(nm) \\
\hline 1 & 27.797 & 3.206 & 0.464 & 488.7 & 0.651 & 18.4 \\
\hline 2 & 32.210 & 2.776 & 0.450 & 1008.65 & 0.622 & 19.1 \\
\hline 3 & 38.094 & 2.306 & 0.647 & 845.25 & 0.992 & 13.5 \\
\hline 4 & 44.195 & 2.047 & 1.204 & 224.79 & 1.535 & 7.43 \\
\hline 5 & 46.250 & 1.961 & 0.576 & 492.67 & 0.702 & 15.6 \\
\hline 6 & 54.750 & 1.675 & 0.532 & 152.66 & 0.722 & 17.5 \\
\hline 7 & 57.450 & 1.602 & 0.610 & 148.96 & 0.825 & 15.4 \\
\hline 8 & 64.485 & 1.443 & 0.367 & 171.27 & 0.758 & 26.6 \\
\hline 9 & 77.068 & 1.236 & 1.285 & 258.17 & 1.368 & 8.25 \\
\hline
\end{tabular}

mechanism involved in each plant varies as due to the presence of different phytochemicals which are involved in the reduction of the ions leads to the synthesis of AgNPs. A strong peak was obtained at 420-430 nm showing the absorption spectra of AgNPs synthesized by $P$. amarus. Further EDX has shown absorption of strong silver signal along with other elements that are bound to the surface of silver nanoparticles. TEM, XRD, DLS revealed the size and zeta potential contributed towards the stability of AgNPs [21]. FTIR confirms the presence of different functional groups absorb characteristic frequencies of IR radiations [22].

The exact mechanism by which silver nanoparticles employ to cause antimicrobial effect is not clearly known.
However, there are various theories suggested about the action of AgNPs on microbes to cause the antimicrobial effect. The AgNPs have ability to anchor to the bacterial cell wall and subsequently penetrate it, thereby causing structural changes in the cell membrane like the permeability of cell membrane and death of the cell. There is formation of 'pits' on the cell surface where accumulation of the nanoparticles takes place [23]. The formation of free radicals by AgNPs may be considered to be another mechanism by which the cells die [24,25]. It has also been proposed that there can be release of silver ions by the nanoparticles [26], and these ions can interact with the thiol groups of many vital enzymes and inactivate them [27]. The bacterial cells in contact with silver absorb silver

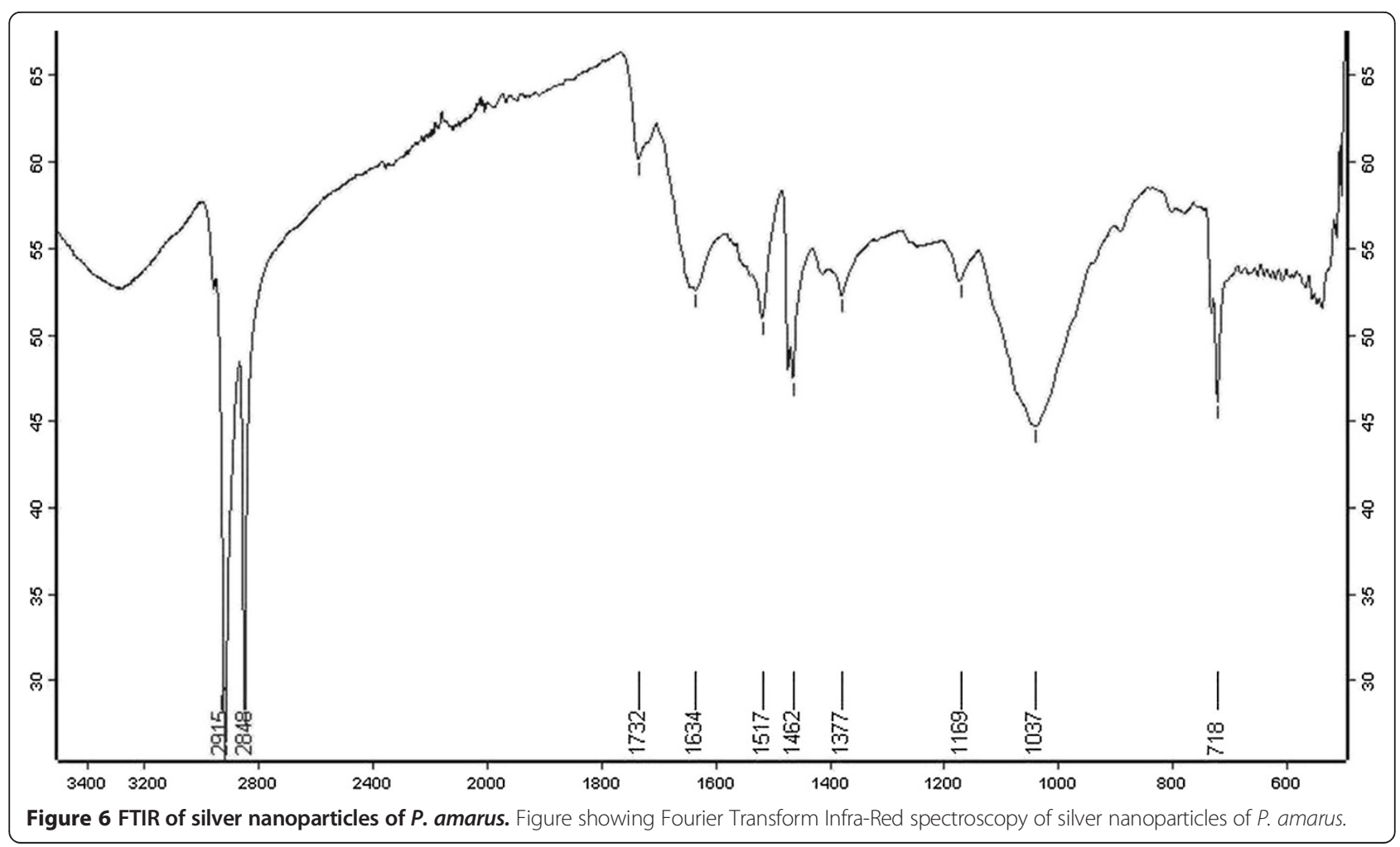




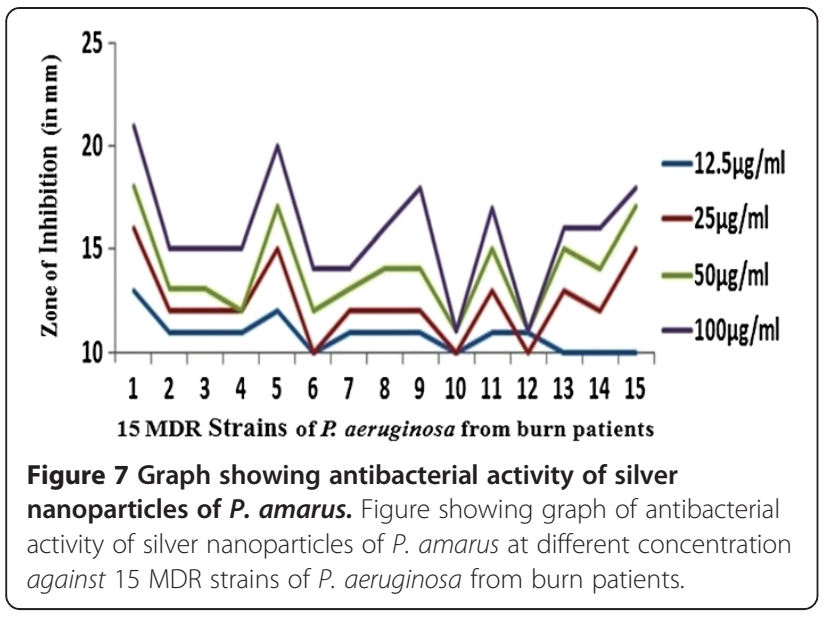

ions, which inhibit several functions in the cell and damage the cells.

In recent years, due to the development of resistant strains, antibiotic resistance also has been increased. MDR $P$. aeruginosa strains from burn patients are causing serious infections and exhibit innate resistance to many antibiotics. These can develop new resistance after exposures to antimicrobial agents. Some antimicrobial agents are extremely irritant and toxic. The studies on drug resistant bacteria in this facet are still limited. Also AgNPs have gained insight as an excellent antimicrobial agent due to its non-toxic effect on human cells in its low concentration and weaker ability to develop resistance towards silver ions [28-30].

The various researchers showed that AgNPs of P. amarus were found to be good antibacterial agent. Humberto et al. [31] showed the antibacterial activity of AgNPs against multidrug-resistant $P$. aeruginosa, E. coli, Streptococcus sp. and S. pyogens. Kathireshwari et al. [32] showed the antimicrobial activity against multi drug resistant human pathogens from leaf mediated synthesis of AgNPs using Phyllanthus niruri. Durairaj et al. [33] studied the antibacterial activity of purchased AgNPs (size 20-30 nm) against 10 isolates of $P$. aeruginosa comprising of 5 MDR strains with an inhibition zone of $11 \mathrm{~mm}$ observed with $10 \mu \mathrm{g}$ dose of the nanoparticles. In our results, AgNPs showed excellent antibacterial activity which is better than our previous study [34], which showed the good antibacterial activity of AgNPs prepared using T. cordifolia aqueous extract against $P$. aeruginosa MDR strain from burn patient with maximum concentration of $200 \mu \mathrm{g} / \mathrm{ml}$. However, there is vital need and much interest in finding ways to formulate new types of safe and cost-effective biocidal materials [22]. Therefore, in this study, we used different plant as biomaterial and evaluated its antibacterial effects. The synthesized AgNPs showed significant antibacterial activity at concentration of $12.5-100 \mu \mathrm{g} / \mathrm{ml}$ against MDR strains of $P$. aeruginosa isolates. The MIC of AgNPs was found to be in a range from $6.25-12.5 \mu \mathrm{g} / \mathrm{ml}$, almost nine MDR strains have shown the MIC at $6.25 \mu \mathrm{g} / \mathrm{ml}$ which was lower than that of the standard antibiotic $(10 \mu \mathrm{g})$. As infection of $P$. aeruginosa always remains one of the most challenging concerns in burn units and the synthesized AgNPs of $P$. amarus are highly effective antibacterial agent against these MDR burn isolates.

\section{Conclusion}

In conclusion, we have demonstrated that AgNPs from $P$. amarus exhibit excellent antibacterial potential against MDR $P$. aeruginosa strains isolated from burn patients. Therefore these AgNPs may act as ecofriendly antibacterial agent against these nosocomial strains and can

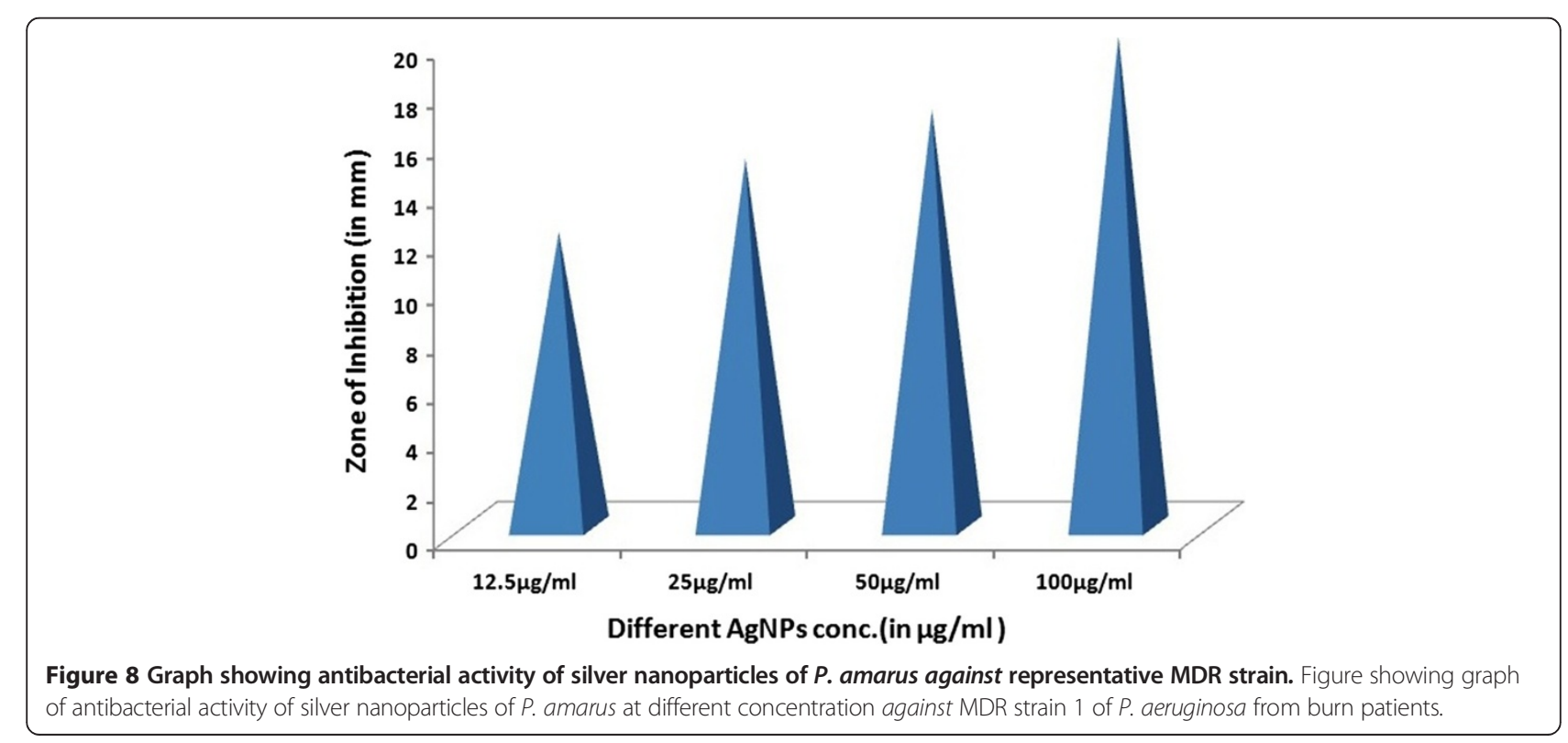


Table 2 MIC of silver nanoparticles of $P$. amarus against MDR strains of $P$. aeruginosa from burn patients

\begin{tabular}{ll}
\hline S.No & MIC(in $\boldsymbol{\mu g} / \mathbf{m l})$ \\
\hline P. aeruginosa MDR Strain 1 & 6.25 \\
P. aeruginosa MDR Strain 2 & 6.25 \\
P. aeruginosa MDR Strain 3 & 6.25 \\
P. aeruginosa MDR Strain 4 & 6.25 \\
P. aeruginosa MDR Strain 5 & 6.25 \\
P. aeruginosa MDR Strain 6 & 12.5 \\
P. aeruginosa MDR Strain 7 & 6.25 \\
P. aeruginosa MDR Strain 8 & 6.25 \\
P. aeruginosa MDR Strain 9 & 6.25 \\
P. aeruginosa MDR Strain 10 & 12.5 \\
P. aeruginosa MDR Strain 11 & 6.25 \\
P. aeruginosa MDR Strain 12 & 12.5 \\
P. aeruginosa MDR Strain 13 & 12.5 \\
P. aeruginosa MDR Strain 14 & 12.5 \\
P. aeruginosa MDR Strain 15 & 12.5 \\
\hline
\end{tabular}

provides a potent alternative nanomedicine in the health care system to reduce the burden of multidrug resistance.

\section{Material and methods}

Synthesis of silver nanoparticles from plant extract Preparation of the extract

The whole plant of Phyllanthus amarus was collected locally from Botanical Garden, M.D. University, Rohtak, Haryana, India. It was thoroughly washed in distilled water, cut into fine pieces. $10 \mathrm{~g}$ of fresh plant material was boiled into $100 \mathrm{ml}$ sterile distilled water for $10 \mathrm{mi}$ nutes and filtered through Whatman's No.1 filter paper. The extract was stored at $4^{\circ} \mathrm{C}$ for further experiments.

\section{Synthesis of AgNPs from plant extract}

For synthesis of AgNPs, the above plant extract of $P$. amarus was used and $15 \mathrm{ml}$ of this extract was added to $200 \mathrm{ml}$ of aqueous silver nitrate solution $(1 \mathrm{mM})$. This solution was kept for 20 minutes at $70^{\circ} \mathrm{C}$ (in water bath). The plant extract act as reducing as well as stabilizing agent in the solution and leads to the formation of AgNPs.

\section{Characterization of synthesized AgNPs}

The seven different characterization techniques were used for AgNPs. At first, AgNPs were characterized by UV-VIS Spectroscopy using Shimadzu UV-VIS Spectrophotometer. The scanning range for the samples was $300-800 \mathrm{~nm}$. The double distilled water used as a blank reference. To remove any free biomass residue or compound that is not the capping ligand of the nanoparticles, after complete reduction, silver nanoparticles were concentrated by repeated centrifugation ( 3 times) of the reaction mixture at $15,000 \mathrm{rpm}$ for $20 \mathrm{~min}$. The supernatant was replaced by distilled water each time. Thereafter, the purified suspension was freeze dried to obtain dried powder. The shape and size of AgNPs was determined by transmission electron microscopy (TEM). A drop ( $2 \mathrm{ul}$ ) of water dissolved synthesized nanoparticles was placed on a copper grid. The images were obtained with a Tecnai, Twin 200 KV (FEI, Netherlands) at a bias voltage of $200 \mathrm{kV}$ used to analyze samples. The composition of the AgNPs was determined using the Energy Dispersive X-Ray Spectroscopy (EDX) coupled to the TEM. The size distribution or average size of the synthesized AgNPs were determined by dynamic light scattering (DLS) and zeta potential measurements were carried out using DLS (Malvern). For DLS analysis the samples were diluted 10 folds using $0.15 \mathrm{M}$ PBS ( $\mathrm{pH}$ 7.4) and the measurements were taken in the range between 0.1 and $10,000 \mathrm{~nm}$. X- Ray Diffraction (XRD) was done with the help of by X-Pert Pro Diffractometer. The X-ray diffraction data were obtained using step scan technique and with $\mathrm{Cu}-\mathrm{Ka}$ radiation $(1.500 \AA, 40 \mathrm{kV}, 30 \mathrm{~mA})$ in $\mathrm{h}-2 \mathrm{~h}$ configuration. The AgNPs were coated on to the glass substrate and after drying, the sample was analyzed by $\mathrm{X}$-ray diffractometer. The crystallite domain size was calculated using the Debye-Scherrer's formula. Finally, Fourier Transform Infra-red Spectroscopy (FTIR) was used for detection of different functional groups. The dried AgNPs were analyzed by ALPHA FT-IR Spectrometer (from Bruker, Germany) for the detection of different functional groups by showing peaks from the region of $4000 \mathrm{~cm}^{-1}$ to $500 \mathrm{~cm}^{-1}$.

\section{Multi drug resistant clinical isolates of $P$. aeruginosa from} burn patients

Fifteen clinical isolates were obtained from the various samples of burn patients receiving in Microbiology Department of Pt. B.D.S. Post Graduate Institute of Medical Sciences, Rohtak, Haryana, India. The purity and identity of each isolate was confirmed in laboratory by standard microbiological methods [35-37]. The sources of the clinical isolates were urine, wounds, blood, and body fluids of burn patients. The approval of SRAC (Scientific \& Research Advisory Committee) of the institute was taken for the study with reference no. UHS/OSD/ 2010/1 dated 27/02/2012. The 10 most cost-effective antibiotics routinely used to treat $P$. aeruginosa infections were employed in the susceptibility test. The antibiotics included were amikacin, aztreonam, ceftizoxime, cefepime, gentamicin, imipenem, netilmicin, ofloxacin, piperacillin and tazobactum. For isolation of MDR strains, these antibiotics were used and susceptibility was checked by Kirby-Bauer disc method [38]. The strain which were resistant to 6 or 7 antibiotics was taken as MDR strain. 


\section{Antibacterial assay of AgNPs}

4 Test samples of the AgNPs were prepared in DMSO (Dimethyl Sulfoxide). The concentrations of AgNPs were ranges from $12.5-100 \mu \mathrm{g} / \mathrm{ml}$ i.e. $12.5,25,50$ and $100 \mu \mathrm{g} / \mathrm{ml}$. The antimicrobial activities were determined by agar well diffusion assay [39]. Under aseptic conditions, in to the Bio safety chamber, $20 \mathrm{ml}$ of MHA medium was dispensed in to pre-sterilized petridishes. Once the media solidifies it was then inoculated with micro-organism suspended in peptone water. The media was then punched with $6 \mathrm{~mm}$ diameter hole and filled with different dilutions (varying from 12.5 to $100 \mu \mathrm{g} / \mathrm{ml}$ ) of AgNPs extract from stock of $20 \mathrm{mg} / \mathrm{ml}$. Streptomycin $(10 \mu \mathrm{g} / \mathrm{ml})$ was used as positive control and DMSO was used as a negative control. Finally, the petridishes were incubated for 24 hours at $37^{\circ} \mathrm{C}$. The diameter of zone of inhibition was measured as indicated by clear area devoid of growth of microbes. Each experiment was done in triplicate.

Minimum inhibitory concentration method (MIC) was calculated by micro broth dilution method in 96 multi-well microtitre plates with slight modifications [40]. Qualitative experimentation was done by resazurin indicator solution prepared by dissolving a $270 \mathrm{mg}$ tablet in $40 \mathrm{ml}$ of sterile distilled water. Purple colour of indicator (resazurin) reduced in the presence of living bacteria. Colour change from purple to pink or to colourless. In the absence of living bacteria the colour of the indicator were remain purple. The lowest conc. at which colour change occurred was taken as MIC.

\section{Consent}

Written informed consent was obtained from the patient for the publication of this report.

\section{Additional files}

Additional file 1: Figure S1. Formation of silver nanoparticles of $P$. amarus. Figure showing colour change from pale yellow to dark brown.

Additional file 2: Figure S2. $U v-V$ is Spectra of silver nanoparticles of $P$. amarus. Figure showing Uv-Vis absorption spectra of silver nanoparticles at range of 300-800.

Additional file 3: Figure S3. Picture of antibacterial activity of AgNPs against $15 \mathrm{MDR}$ strains of $P$ aeruginosa. Figure showing antibacterial activity of AgNPs against 15 MDR strains of $P$ aeruginosa at concentration of $12.5-100 \mu \mathrm{g} / \mathrm{ml}$.

\section{Competing interests}

The authors declare that they have no competing interests.

\section{Authors' contributions}

KS contributed to the design of the study, performed the experiment, analyzed the data and prepared the manuscript. MP maintained the bacterial sample culture. SK contributed in the analysis of data. UC provided the bacterial samples. JPY was responsible for the research and the manuscript. All authors read and approved the final manuscript.

\section{Acknowledgements}

The authors are thankful to National Medicinal Plant Board (Grant no \& Date- Z.18017/187/CSS/R\&D/HR-01/2011-12-NMPB/24/11/2011), New Delhi for the award of Major Research Project grant and Department of Science \& Technology (DST) for providing fund for project (Grant no - SR/WOS- A/LS-259/2011(G) \& Date- 19/12/2011).

\section{Author details}

'Department of Genetics, M.D. University, Rohtak 124001, Haryana, India. ${ }^{2}$ Department of Microbiology, Pt. B.D.S Post Graduate Institute of Medical Sciences Rohtak, Rohtak 124001, Haryana, India.

Received: 29 May 2014 Accepted: 18 September 2014

Published online: 01 October 2014

\section{References}

1. Santucci SG, Gobara S, Santos CR, Fontana C, Levin AS: Infections in a burn intensive care unit: experience of seven years. J Hosp Infect 2003, 53:6-13.

2. Cochran A, Morris SE, Edelman LS, Saffle JR: Systemic Candida infection in burn patients. Surg Infect Larch 2002, 3:367-374.

3. Marcato PD, Duran N: New aspects of nanopharmaceutical delivery systems. J Nanosci Nanotechnol 2008, 8:2216-2229.

4. Singh $\mathrm{R}$, Singh $\mathrm{NH}$ : Medical applications of nanoparticles in biological imaging, cell labeling, antimicrobial agents, and anticancer nanodrugs. J Biomed Nanotechnol 2008, 7:489-503.

5. Morones JR, Elechiguerra JL, Camacho A, Ramirez JT: The bactericidal effect of silver nanoparticles. Nanotechnology 2005, 16:2346-2353.

6. Kurek A, Grudniak AM, Kraczkiewicz-Dowjat A, Wolska KI: New antibacterial therapeutics and strategies. Pol J Microbiol 2011, 60:3-12.

7. Percival Steven L, Bowler PG, Dolman J: Antimicrobial activity of silver-containing dressings on wound microorganisms using an in vitro biofilm model. Int Wound J 2007, 4:186-191.

8. Gemmell CG, Edwards DI, Frainse AP: Guidelines for the prophylaxis and treatment of methicillin-resistant Staphylococcus aureus (MRSA) infections in the UK. J Antimicrob Chemother 2006, 57:589-608.

9. Shankar SS, Rai A, Ahmad A, Sastry MJ: Rapid synthesis of Au, Ag and bimetallic Au-shell nanoparticles using Neem. J Colloid Interf Sci 2004, 275:496-502.

10. Raut RW, Lakkakula JR, Kolekar NS, Mendhulkar VD, Kashid SB: Phytosynthesis of silver nanoparticle using Gliricidia sepium (Jacq.). Curr Nanosci 2009, 5:117-122.

11. David SG: Bionanotechnology: Lessons from Nature. New York: Wiley; 2004.

12. Talebi S, Ramezani F, Ramezani M: Biosynthesis of metal nanoparticles by micro-organisms. Nanocon Olomouc, Czech Republic, EU 2010, 10:12-18.

13. Patel JR, Tripathi P, Sharma V, Chauhan NS, Dixit VK: Phyllanthus amarus: ethnomedicinal uses, phytochemistry and pharmacology: a review. J Ethnopharmacol 2011, 138:286-313.

14. Oza G, Pandey S, Shah R, Sharon M: Extracellular fabrication of silver nanoparticles using Pseudomonas aeruginosa and its antimicrobial assay. Pelagia Res Lib Adv App/ Sci Res 2012, 3:1776-1783.

15. Ahmad I, Beg AZ: Antimicrobial and phytochemical studies on 45 Indian medicinal plants against multiple drug resistant human pathogens. J Ethanopharmacol 2001, 74:113-123.

16. Sharma A: Antibacterial activity of ethanolic extracts of some arid zone plants. Int J Pharm Tech Res 2011, 3:283-286.

17. Mazumder A, Mahato A, Mazumder R: Antimicrobial potentiality of Phyllanthus amarus against drug resistant pathogens. Nat Prod Res 2006, 20:323-326.

18. Prabhu S, Poulose E: Silver nanoparticles: mechanism of antimicrobial action, synthesis, medical applications, and toxicity effects. Int Nano Lett 2012, 2:32. doi:10.1186/2228-5326-2-32.

19. Yuandani, llangkovan M, Jantan I, Mohamad HF, Husain K, Abdul Razak AF: Inhibitory effects of standardized extracts of Phyllanthus amarus and Phyllanthus urinaria and their marker compounds on phagocytic activity of human neutrophils. Evid Based Complement Alternat Med 2013, 2013:603634.

20. Jha AK, Prasad K, Prasad K, Kulkarni AR: Plant system: nature's nanofactory. Colloids Surf B: Biointerfaces 2009, 73:219-223.

21. Bunghez IR, Barbinta Patrascu ME, Badea NM, Doncea SM, Popescu A, Ion RM: Antioxidant silver nanoparticles green synthesized using ornamental plants. J Optoelectronics Adv Mater 2012, 14:1016-1022. 
22. Kalainila P, Subha V, Ernest Ravindran RS, Sahadevan R: Synthesis and characterization of silver nanoparticles from Erythrina indica. Asian $J$ Pharm and Clin Res 2014, 7:39-43.

23. Sondi I, Salopek-Sondi B: Silver nanoparticles as antimicrobial agent: a case study on E. coli as a model for Gram-negative bacteria. J Colloid Interface Sci 2004, 275:177-182.

24. Danilcauk M, Lund A, Saldo J, Yamada H, Michalik J: Conduction electron spin resonance of small silver particles. Spectrochimaca Acta Part A 2006, 63:189-191.

25. Kim JS, Kuk E, Yu K, Kim JH, Park SJ, Lee HJ, Kim SH, Park YK, Park YH, Hwang CY, Kim YK, Lee YS, Jeong DH, Cho MH: Antimicrobial effects of silver nanoparticles. Nanomedicine 2007, 3:95-101.

26. Feng QL, Wu J, Chen GQ, Cui FZ, Kim TN, Kim JO: A mechanistic study of the antibacterial effect of silver ions on Escherichia coli and Staphylococcus aureus. J Biomed Mater Res 2008, 52:662-668.

27. Matsumura Y, Yoshikata K, Kunisaki S, Tsuchido T: Mode of bacterial action of silver zeolite and its comparison with that of silver nitrate. Appl Environ Microbiol 2003, 69:4278-4281.

28. Shahverdi AR, Fakhimi A, Shahverdi HR, Minaian S: Synthesis and effect of silver nanoparticles on the antibacterial activity of different antibiotics against Staphylococcus aureus and Escherichia coli Nanomed. Nanotechol Biol Med 2007, 3:168-171.

29. Sukhdeb P, Kyung TY, Myong SJ: Does the antibacterial activity of silver nanoparticles depend on the shape of the nanoparticle? A study of the gram-negative bacterium Escherichia coli. Appl Environ Microbiol 2007, 73:1712-1720.

30. Sharma Virender K, Yngard RA, Yekaterina L: Silver nanoparticles: green synthesis and their antimicrobial activities. Adv Colloid Interface Sci 2009, 145:83-96.

31. Humberto HL, Ayala-Nunez NV, del Carmen Ixtepan Turrent L, Padilla CR Bactericidal effect of silver nanoparticles against multidrug- resistant bacteria. World J Microbiol Biotechnol 2010, 26:615-621.

32. Kathireswari P, Gomathi S, Saminathan K: Plant leaf mediated synthesis of silver nanoparticles using Phyllanthus niruri and its antimicrobial activity against multi drug resistant human pathogens. Int J Curr Microbiol App Sci 2014, 3:960-968.

33. Durairaj R, Amirulhusni AN, Palanisamy NK, Mohd-Zain Z, Ping L: Antibacterial effect of silver nanoparticles on multi drug resistant pseudomonas aeruginosa. World Acad Sci Eng Technol 2012, 6:210-213.

34. Singh K, Panghal M, Kadyan S, Chaudhary U, Yadav JP: Antibacterial activity of synthesized silver nanoparticles from Tinospora cordifolia against multi drug resistant strains of Pseudomonas aeruginosa isolated from burn patients. J Nanomed Nanotechnol 2014, 5:192. doi:10.4172/2157-7439.1000192.

35. Hawkey P, Law DA: Medical Bacteriology: A Practical Approach. New York: Oxford University Press; 2004

36. Ryan KJ: Normal Microbial flora. In Medical Microbiology. 4th edition. Edited by Sherris JC, Ryan KJ, Ray GC. USA: McGraw Hill; 2004.

37. Pawar VB, Dutta D: From Diagnostic Bacteriology. In A Procedure Manual for Routine Diagnostic Test, Volume 2. Edited by Mukherjee KL. New Delhi: Tata MacGrew -Hill Publishing Company Limited; 2006:554-626.

38. Bauer AW, Kirby WM, Sherris JC, Turck M: Antibiotic susceptibility testing by a standardized single disk method. Am J Clin Pathol 1966, 45:493-496.

39. Perez C, Pauli M, Bezevque P: An antibiotic assay by agar well diffusion method. Acta Biologiae Med Experimentalis 1990, 15:113-115.

40. Sarker SD, Nahar L, Kumarasamy Y: Microtitre plate-based antibacterial assay incorporating resazurin as an indicator of cell growth, and its application in the in vitro antibacterial screening of phytochemicals. Methods 2007, 42:321-324.

doi:10.1186/s12951-014-0040-x

Cite this article as: Singh et al:: Green silver nanoparticles of Phyllanthus amarus: as an antibacterial agent against multi drug resistant clinical isolates of Pseudomonas aeruginosa. Journal of Nanobiotechnology 2014 12:40.

\section{Submit your next manuscript to BioMed Central and take full advantage of:}

- Convenient online submission

- Thorough peer review

- No space constraints or color figure charges

- Immediate publication on acceptance

- Inclusion in PubMed, CAS, Scopus and Google Scholar

- Research which is freely available for redistribution

Submit your manuscript at www.biomedcentral.com/submit 